\title{
Designing for Diagnosing: Introduction to the Special Issue on Diagnostic Work
}

\author{
Monika Büscher ${ }^{1}$, Jacki O’Neill ${ }^{2,4} \&$ John Rooksby ${ }^{3}$ \\ ${ }^{1}$ Department of Sociology, Lancaster University, Lancaster, UK; ${ }^{2}$ Xerox Research Centre Europe, \\ Meylan, France, ${ }^{3}$ School of Computer Science, University of St Andrews, Scotland, UK; ${ }^{4} 6$ Chemin \\ de Maupertuis 38240 Meylan, France (E-mail: Jacki.oneill@xrce.xerox.com)
}

\begin{abstract}
When faced with anything out of the ordinary, faulty or suspicious, the work of determining and categorizing the trouble, and scoping for what to do about it (if anything) often go hand in hand - this is diagnostic work. In all its expert and non-expert forms diagnostic work is often both intellectual and embodied, collaborative and distributed, and ever more deeply entangled with technologies. Yet, it is often poorly supported by them. In this special issue we show that diagnostic work is an important and pervasive aspect of people's activities at work, at home, and on the move. The papers published in this Special Issue come from a range of domains including, ambulance dispatch, a friendly fire incident and anomaly response for the NASA space shuttle; software, network and photocopier troubleshooting; and users attempting to use a new travel management system. These papers illustrate the variety of work that may be thought of as diagnostic. We hope that bringing a focus on diagnostic work to these diverse practices and situations opens up a rich vein of inquiry for CSCW scholars, designers, and users.
\end{abstract}

Key words: diagnosis, diagnostic work, ethnography

\section{Introduction}

"I once heard that when Petrov was a young physician, years ago, he occasionally made definite diagnoses, and these were often quite correct. But with the vast increase in medical technology, and with it so many new considerations to take into account, he's limited himself...."

Alan Lightman (2000) The Diagnosis. London: Bloomsbury: p. 112

Bill Chalmers, the protagonist in Alan Lightman's novel The diagnosis is debilitated by a mystery illness. As his doctors persistently fail to provide a diagnosis, his world unravels. A diagnosis, even one that subsequently proves 
incorrect, can be critical to people's efforts of making and holding their worlds together; in Bill Chalmers' case it could not only have explained symptoms, but opened doors for treatments, support, sick leave, insurance claims and so on. This need for a diagnosis spreads well beyond healthcare. When faced with anything out of the ordinary, faulty or suspicious, the work of determining and categorising the trouble, and scoping for what to do about it (if anything) often go hand in hand. We are calling such work "diagnostic work".

Diagnostic work is practiced by medical professionals, but also by detectives, engineers, designers, helpline operators, emergency response personnel, architects, builders, managers, to name but a few. Diagnosis by professionals can be a specialised skill, carry heavy responsibilities, and sometimes be undertaken in exceptional and highly stressful situations. But ordinary people, in mundane situations, also frequently practice diagnostic work. For example, most people have tried to determine how a new technology works (or why it doesn't). In all its expert and non-expert forms diagnostic work is often both intellectual and embodied, collaborative and distributed, and ever more deeply entangled with technologies. Yet, it is often poorly supported by them.

In this special issue we show that diagnostic work is an important and pervasive aspect of people's activities at work, at home, and on the move. We deliberately invited and put together contributions that address a range of different, mainly non-medical settings, because bringing a focus on diagnostic work to these diverse practices and situations opens up a rich vein of inquiry for CSCW scholars, designers, and users. The collection is informed by interdisciplinary discussions during two workshops ${ }^{1}$, an open call, and a peer review process which have explored many questions of consequence for CSCW. In this introduction we draw out key characteristics of diagnostic work and highlight issues and opportunities for CSCW.

\section{Diagnostic work}

A central issue that emerged in discussions with participants at our workshops, as well as the contributors and reviewers to this issue was that (at first glance paradoxically) diagnostic work does not always produce definite diagnoses, nor is it necessarily designed to do so. We came across many cases where a 'good enough' or implicit diagnosis sufficed to explain or move work forward. In the papers in this special issue we find computer programmers performing workarounds or a 'quick fix' (Alby and Zucchermaglio), or users who have asked for help satisfied when their technology is working again (Castellani et al., Poole et al, Arminen and Poikus), without a definite diagnosis ever being required. In other situations, definitive diagnoses may be the goal of work: NASA engineers assessing whether an anomaly is mission critical need to categorize and name events to determine causes and likely future effects (Watts-Perotti and Woods), and call takers for emergency services need to put a label on incidents to know 
what kind of help to dispatch (Paoletti). But focusing mainly on 'the diagnosis' draws attention away from the means of producing it, the circumstances, the rationalities, the blind alleys followed, and the (dissipation of) motivation.

By switching attention from product to process, from diagnosis to diagnostic work, we hope to demystify certain aspects of diagnosing, and particularly to challenge the notion that diagnosing is exclusively intellectual work done by individual experts. Diagnostic work is often portrayed as a sophisticated process of forming, weighing up and testing hypotheses to determine the underlying causes of, or events or actions that led to, undesirable effects. In emergency situations, for example, 'situation awareness' is said to require accurate perception and comprehension of what is going on, its causes and implications, with parallels to diagnosis in medical settings (Singh et al. 2006). Professionals are expected to gain situation awareness swiftly, dynamically and accurately to inform decision making (Endsley et al. 2003), and diagnostic ability is regarded as a core skill for emergency personnel, especially incident commanders (Flin 2005). It is mainly seen as a cognitive skill that requires individuals to process large amounts of diverse sensory and discursive information and form a mental model of the situation. Research suggests that experience can help professionals build schemata of typical situations, increasing their processing efficiency (Endsley et al. 2003) and that they acquire pattern matching abilities, which enable recognition-primed decisions and mental simulations of possible courses of action (Klein 1998). The potential of designing technologies for diagnosing is seen to lie in bringing together and visualizing large amounts of information (Tomaszewski and MacEachren 2006), in supporting human information processing capabilities, for example through algorithmic anomaly detection (Pawling et al. 2007), 'information fusion' and semantic webs (Smart et al. 2005), and in enabling more effective relaying and organization of information (Bitner et al. 2008). Although seductively satisfying as explanations on the surface, such accounts of diagnostic work and visions for technological support can overlook or mystify important practices, not least because they are based on representational or correspondence theories of facts and descriptions, (for critiques see Wittgenstein 1953; Garfinkel and Sacks 1970; Barad 2007; Thrift 2008). While we appreciate many of the insights provided by research into 'diagnosis' based on cognitivist models, we fundamentally disagree with the frame of enquiry and its focus on individual rational, cognitive, and psychological abilities Naturalistic studies of practice, a field to which this special issue seeks to contribute, challenge such assumptions.

\subsection{Why CSCW and diagnostic work?}

We ask questions about diagnostic work in the context of CSCW for three reasons. Firstly, across a wide range of perspectives and objects of diagnosis, people work collaboratively, using technologies to produce diagnoses. However, 
rarely are these 'technologies' in and of themselves diagnostic. Technologies can support people in comparing, for example, the colours of different soils collected in a 'pedocomparator' and a Munsell chart (Latour 1999); they allow people to classify, for example, through the use of diagrammatic field-guides in bird watching (Law and Lynch 1990); and they embody mechanisms of articulation work, for example, to follow the nature and status of interdependent work as it progresses (Schmidt and Bannon 1992). In medicine, technologies help to enrol patients as expert witnesses in the objectification of their own bodies and the 'ontological choreography' of diagnostic work (Cussins 1998), they open up new trajectories for further interventions and moral choices (Franklin and Roberts 2006), raising questions about the appropriateness of enactments of the 'body multiple' (Mol 2002). Rule-based 'expert system' technologies may usefully prompt diagnosing actors, but also require them to develop biographies for the machine, defining what features it might be good and bad at prompting for-a social and interactional accomplishment (Hartswood et al. 2003). Disregard for the interactional work that is critical to diagnosis can necessitate onerous workarounds for users of diagnostic technologies and produce severe troubles also in non-medical settings, such as office device troubleshooting (Whalen and Vinkhuyzen 2001).

Secondly, the often collaborative and embodied interactional work of diagnosis is frequently distributed, mediated through the use of more or less sophisticated communication technologies, be it between doctors, nurses and patients (Hansen et al. 2007), troubleshooters and customers (Castellani et al., Poole, Edwards and Jarvis, this issue), pilots and ground control (Nevile, this issue), emergency dispatchers and on the scene witnesses or first responders (Paoletti, this issue), or engineers (Watts-Perotti and Woods, this issue). The importance and difficulty, but also the opportunities for supporting collaboration and communication can hardly be overestimated when designing for diagnosing.

Thirdly, much diagnostic work is done to understand what technologies are doing, what they could or should do and - if they are not functioning — why they are not working (see especially Arminen and Poikus, Castellani et al. Poole, Edwards and Jarvis, this issue). Support for 'collaboration' between people and technologies has been a long-standing concern in CSCW, first raised by Suchman's $(1987$, 2007) examination of human-machine 'communication' and configurations. A number of approaches have been developed, including attempts to use computational reflection for 'accountable' computing (Dourish 1995' 2001; Dourish and Button 1998; De Paula et al. 2005); 'seamful design' (Chalmers 2003); HCI approaches designed to help technologies to monitor themselves, help users to understand their functioning, and to support others in helping users understand (Shehan and Edwards 2007); computational approaches, such as datamining, allowing machines to monitor their state and report this to relevant parties - be these users or technical experts (see for example; Bouchard and Andreoli 2007; Breese and Heckerman 1996); participatory design for appropri- 
ate, recipient designed accounts (Anderson et al. 2003); 'designs that support people in making computing palpable' (Kyng 2007; Büscher et al. 2008). The matter is increasingly recognised as important, as analytical sensitivities and design philosophies developed within $\mathrm{CSCW}$ reveal their relevance to new technological potential and domains of activity, for example, in pervasive and grid computing (Bellotti et al. 2002; Jirotka et al. 2005).

\section{Thematic overview}

In this section we provide an overview of the papers collected in this special issue, using their concrete empirical examples to map out four key themes that arise from them and the many conversations about diagnostic work and sociotechnical innovation that underpin this special issue. All seven papers involve substantial analysis of particular problems, situations and settings, creating a diversity of focus which includes: troubleshooting web servers or office devices such as printers and photocopiers, patrolling a battlefield, analysing mission anomalies at NASA, dispatching emergency vehicles, working out how to use new software, and providing helpline support for home networks. Despite this diversity, significant family resemblances in the work described mean that all seven papers speak to all four themes (and more).

\subsection{The social and organizational logics of diagnostic work}

First and most importantly, diagnostic work is a social phenomenon. Two of the papers in this issue complement each other very effectively, providing stimulating insight by examining co-present and distributed, technologically mediated collaboration respectively.

Alby and Zucchermaglio, in their paper Time, narratives and participation frameworks in software trouble shooting describe different aspects of the sociality of diagnostic work over different phases of web designers' response to a 'site down' alarm. The urgency of one designer's 'out loud' alert (Heath and Luff 1992) immediately brings colleagues to gather around the head engineer's screen to work together to understand and address the problem. An initial diagnosis is produced through collaborative interaction with the website, followed by a frantic search for a quick fix that would hide the fault (scrambled contents) from the users: 'do something'! This swiftly negotiated situated social logic of diagnosis as a 'backstage' matter also highlights the import of the designers' ever-present social relation with users and their need to manage appearances across front-stage and backstage regions (Goffman 1969; Sharrock and Anderson 1994).

Alby and Zucchermaglio then draw attention to the frequent lack of separation between diagnosis and intervention, as 'attempts at repair support the diagnostic work'. While 'the designers do not know where they are going until after they have seen the results of the intervention' the process clearly develops the team's 
shared understanding of the problem. Soon, they are no longer 'operating' in full view of the public, and another level of diagnostic work opens up. But as the designers delve into a slower and deeper search for causes, they discover that they would have to inspect 'millions and millions of logs' to get to the bottom of the problem, and they lose interest. Even though a thorough investigation might prevent a re-occurrence, an organizational logic that values speed over perfection makes it more sensible to return to other priorities and allow the problem "to "dissolve" rather than being "solved". Clearly, any technology would have to respect, or ideally support, this dynamic negotiation of levels and orientations towards diagnostic work.

Nevile's paper "You are well clear of friendlies": Diagnostic error and cooperative work in an Iraq War friendly fire incident is a careful investigation of a tragic incident of 'friendly fire' during the early stages of the Iraq war. Nevile reveals further crucial dimensions of the sociality of diagnostic work. Through close study of distributed collaboration between two pilots and a ground controller, he brings into view the delicately produced nature of shared understanding. Flying at speed over hazy desert ground, pilot Popov 35 talks to a ground controller, trying to work out what should be done about a known group of hostile vehicles. Meanwhile, Popov 36, the second pilot in this two plane team, spots another group of vehicles. He overhears his colleagues' conversation and now uses a pause between them to announce his observation to Popov 35, voicing the possibility that they may be 'friendlies', but asking for reassurance: 'are there any friendlies up in this area?'. At this point, the ground controllerwho is unable to overhear conversations between pilots - requests a location confirmation from Popov 35, referring to the first, known to be hostile, group of vehicles (the only one he is aware of). Popov 35 provides the location, and, in the same turn, also asks for confirmation that there are 'no friendlies this far north on the ground'. The ground controller obliges: 'you are well clear of friendlies'. The exchange - asymmetric with regard to who can hear who-results in apparent simplicity of reference and clarity of meaning, but actually harbours fateful confusion. Accepting the epistemic authority of the remote ground controller whose access to maps and multiple reports could provide a better overview than a view out of a cockpit window, the pilots' logical — and urgent — next move is to attack the second group of vehicles spotted by Popov 36 .

Nevile unravels how the incident is an effect of the way in which the world is evolving around the participants as they work, promoting and enabling a "new view' of diagnostic error (Dekker 2005). Understanding that dependability of practice is an accomplishment that requires complex orchestration between multiple actors and agencies (ibid., Martin et al. 2006), Nevile shows clearly how unhelpful a focus on 'human error' can be. He not only draws attention to the well known struggles of fragmented, disembodied conduct (Heath and Luff 1992), but also to the insidious strength of everyday idealizations of reciprocity of perspective. As Schutz so acutely observed 'until counter-evidence I take it for 
granted - and assume my fellowman does the same - that the differences in perspectives... are irrelevant for the purposes at hand' (Schutz 1970, p. 183). In the friendly fire incident Nevile exhibits so painstakingly, this idealization overrides knowledge of technologically induced fragmentation as well as procedures to circumvent them. People's current sensorium, social radar, and reasoning seems ill equipped to dwell effectively in fragmented distributed environments without adequate support through system design: a core challenge for $\mathrm{CSCW}$.

\subsection{Multiple agencies and actors}

Frequently in diagnostic work multiple agencies and actors are involved (although not always acknowledged), there is interdisciplinary collaboration and there are multiple means of making material agencies 'speak' (Suchman 1987; Latour 1999; Barad 2007; Büscher et al. 2009). The papers in this special issue show the relevance of such factors to understanding diagnostic work, and that there are no simple ways and certainly no guarantees for ensuring its accuracy and timeliness.

Watts-Perotti and Woods in Cooperative Advocacy: An approach for integrating diverse perspectives in anomaly response provide rich empirical grounding and conceptual resources by developing the notion of 'cooperative advocacy' through a stirring comparison of successful and unsuccessful anomaly response in NASA space missions. Anomaly response is a particular form of diagnostic work, concerned with recognising events that are anomalous, determining their significance and implications in potentially massively interdependent systems and cascading sets of disturbances, and determining how to deal with them.

Watts-Perotti and Woods had the rare opportunity to observe and document a successful anomaly response episode during a shuttle mission to transport an American astronaut to the Russian MIR space station. Usually successes are not well documented or publicised, nowhere near as extensively as failures, such as the 2003 Columbia disaster, where seven crew members lost their lives on the shuttle's re-entry into the earth's atmosphere. By contrasting the processes and interactions across groups working together in these missions, Watts-Perotti and Woods are able to describe strategies that can help avoid the danger of 'premature narrowing' (Woods and Hollnagel 2006; Klein et al. 2005). Most effective among these is an approach of 'cooperative advocacy', which requires multiple actors to be in a position to speak out on behalf of the material agencies involved in the shuttle mission from their respective perspectives and be listened to.

In the successful anomaly response incident, conditions and procedures were favourable to a continued effort of cooperative advocacy. Flight controllers, hydraulics engineers, operations managers, and crew representatives met frequently - formally and by 'bumping into each other' - and discussed the 
complexities of the case. In the disastrous Columbia case, the anomaly response effort was, from the very start, made more difficult by the fact that the anomalya foam strike (debris hitting the shuttle) - was categorically classified as not safety critical before it had even been investigated. Furthermore, the different groups involved were disconnected, working in isolation and allowed to continue to do so, leading to a lack of ownership of the responsibility for the anomaly. In both cases the diagnostic work is not so much about establishing the causes of the hydraulics leak or the foam strike, but about envisaging futures and managing them.

This paper highlights very effectively that multiple agencies are involved and complexly interconnected. Although not all situations are as complex or ambitious as a space mission, Watts-Perotti and Woods' analysis provides important general insight. It complements discussions about the 'tacit order of teamwork' (Hindmarsh and Pilnick 2002), or studies of the ways in which people encourage others to become sensitive to particular events (Heath et al. 2002). The concept of cooperative advocacy may be fruitfully applied and enriched by these studies as well as investigations that draw on insights from science and technology studies, such as, for example Dawn Goodwin's studies of humanmachine relations in anaesthesia (Mort et al. 2005; Goodwin 2009a). Moreover, by highlighting the need to consider material agencies' behaviour continuously and from different perspectives, the notion of cooperative advocacy can - slightly paradoxically - also contribute to studies of individual diagnostic work, as for example, in piano tuning (Sudnow 1978, p. 44).

\subsection{The entanglement of diagnosis and intervention}

From the studies discussed so far some indication for why explicit 'diagnoses' are rare can be gleaned. Diagnoses can be important but very difficult to come by; yet they can also be (regarded as) unnecessary: web-designers who fix troubles before they really know what has happened and lose interest in diagnosis when the time and effort needed to construct it is revealed (Alby and Zucchermaglio, this issue) attest to this, as do the implicit, 'negative' diagnoses that put pilots under pressure to act (if the vehicles they are seeing are not 'friendlies', they must be enemies; Nevile, this issue). Diagnostic work clearly is much more, and much more pervasive than 'diagnosis'. Two of the studies in this special issue very effectively further illuminate the entanglement of diagnostic work, diagnosis, 'probing', intervening and acting.

Castellani, Grasso, O'Neill and Roulland's paper Designing technology as an embedded resource for troubleshooting is a study of troubleshooters' engagement with customers who are experiencing troubles with their office devices. This paper exhibits incisively how elusive, multi-level, ephemeral, evaded, important but also irrelevant, diagnoses can be. After an initial problem description by the customer, Castellani et al. show how the remote troubleshooters manoeuvre extremely delicately to move the interaction onto a footing where customers 
become collaborators in identifying and ideally addressing the problem. Troubleshooters coax, cajole and in the process coalesce diagnosis and intervention: "I tell you what, are you near the machine yourself, Caroline? Could you just do a little test for me?" But collaborative goodwill on the customer's side is brittle and at each moment hinges on unfolding shared understanding. Diagnoses - unspoken, unknown (and unknowable without further investigation) - haunt this interaction, and the slightest indication that troubleshooters' may be leading one up the garden path, result in contestation or refusal to continue the intervention. At the same time, diagnoses can quickly become irrelevant - often achievable only in the resolution of the problem, by which point they may no longer be necessary.

Moreover, apart from multiple levels of intermediate 'good enough', implicit working diagnoses, there are multiple diagnostic objects. As well as diagnosing faulty office equipment with their customers, troubleshooters are performing diagnostic work 'on' their customers, assessing their technical competence (Baker et al. 2005) and trying to understand where they are in the sequential and spatial organization of the troubleshooting activity so that instructions can be recipient designed more precisely. Much of the latter is blind, and, drawing on Lucy Suchman's (2007) analysis of human-machine configurations, Castellani et al. provide powerful conceptual tools for analysis and design. By richly describing multiple physical, conceptual and logical 'dislocations' that both customers and troubleshooters must work around to get the job done, Castellani et al. are able to identify important opportunities for CSCW design.

Their aim is an integrated system that enables customers to move more smoothly and effectively between different configurations: from device-suggested solutions to self-troubleshooting guided by an on-device knowledge base, to expert supported troubleshooting. In the authors' interdisciplinary teams, distinctions between ethnographers and designers are blurred, and located accountabilities for design (Suchman 2002) as well as deep sensitivity to work practices are coming together creatively, allowing Castellani et al. to develop and validate highly innovative conceptual designs that embed technology as a resource into office equipment, supporting shared understanding and collaboration. The application of CSCW design philosophies all the way through to experimental validation - ethnographically studied, documented and iteratively fed back into design - produces invaluable insights for emergent fields of technological innovation, such as the 'Internet of Things' (Floerkemeier et al. 2008). Castellani et al. find, for example, that by embedding resources for reasoning in the office devices, users developed new expectations around 'what the system knows', assuming a logical connection between their specific ailing device and the information drawn from the knowledge base. Such expectations must be responded to by design, not necessarily by fulfilling them, but at least by anticipating and addressing them, and if necessary breaking them (Bly et al. 2006), but in a way that makes this clear to users. 
Paoletti's paper Communication and diagnostic work in medical emergency calls in Italy presents an analysis of the erroneous dispatch of a helicopter rescue team to attend to an already dead victim of a work accident. It reveals the tensions between diagnostic work, diagnosis, intervening and acting in a more dramatic and highly stressful situation. In the case of calls to the Italian emergency number 118, according to protocols and to the distress of the call taker, also according to post-event reprimands she receives, 'diagnosis' is essential and must be prior to dispatch of appropriate response measures. However, as Paoletti examines the communications between a call taker in a regional emergency call centre, a number of witnesses (with partial knowledge), and first responders at the scene, it becomes evident that diagnosing and dispatching are necessarily intertwined activities.

Paoletti's investigation also shows that the need for situation awareness or shared understanding is multi-directional. Most importantly, callers seem to need to understand at least some of the call takers' organizational background. In the past, calls to the emergency number contacted the accident and emergency centre at a local hospital, whence an ambulance would be sent to fetch the patient. This understanding informs the first callers' approach. He asks, very urgently, for an ambulance to be sent. However, from the relatively new regional centres, dispatchers can effectively send 'miniature hospitals' to the patient to attend to their injuries at the scene. Alas, this institutional change (unknown to the caller) means that dispatchers need to establish a much more detailed understanding of the nature of the accident and the condition of the patient and bear in mind larger scale demands on mobile resources. When this leads the dispatcher to question the first caller, it becomes apparent that he has been sent to report without actually having seen the incident or the patient, and he now is in a location with a telephone, but remote from the scene. What is more, to the caller the dispatcher's questions appear to delay the sending of the ambulance. As the dispatcher attempts to inform the caller of the underlying institutional protocols, the exchange escalates at an incredible speed, ending up with the caller putting the phone down on the dispatcher. From here, things go from bad to worse, as conflicting information is provided with great haste and urgency over faulty audio connections. From the dispatcher's perspective, a life is at stake and a helicopter with a rescue team seems the only appropriate response. From the perspective of staff on the ground - first the ambulance team and later the helicopter crewcostly resources are mobilized in vain, as the patient was evidently dead even when the first call was made.

Paoletti's paper illustrates powerfully how understandings of diagnostic work that naturalize a 'cognitivist' model can get in the way of doing the work needed effectively, contrasting but also resonating very usefully with the work described by Castellani et al. In both cases representing, intervening and formulating (Hacking 1983; Garfinkel and Sacks 1970) are intertwined. Where call takers coax customers to collaborate in distributed troubleshooting activities, interven- 
tion often has an epistemic as well as a practical purpose (opening a door on a photocopier not only makes visible what is inside, it also enables the customer to remove paper stuck between rollers, for example). In the distributed collaboration between witnesses with partial knowledge and access to often chaotic, dangerous incident scenes and emergency response resource dispatchers, the situation is different. Usually, those on the scene are unable and should not attempt to intervene, not least for their own safety. People and resources who are able to intervene must be mobilized swiftly. Despatch is thus the first intervention. It is 'abstract' in the sense of having no immediate epistemic or practical purchase on the situation. However, it can be progressively tailored to be ready on arrival through the use of additional information. While in the distributed troubleshooting Castellani et al. describe, the epistemic and practical implications of intervention for diagnosis are available to both parties, the abstract nature and hidden dependence on rich information of intervention in the emergency case reported here are not available to the caller. Acknowledgement and explication could significantly enhance the dispatchers' ability to elicit information and tailor help to the specific situation. This is not only an organizational matter, where revised protocols could allow call takers to 'read back' what they are doing to inform callers about their actions and interactional motivations which has proved highly effective in managing reports of trouble in other settings (Houtkoop et al. 2005), or a matter for educating the public, it is also a matter for design. This is especially true as new multi-media mobile phones are increasingly used to report incidents, witnesses or otherwise involved parties turn to generating information (Palen and Liu 2007), and professionals are beginning to use mobile and pervasive computing technologies to support emergency response teamwork (Büscher and Mogensen 2007; Büscher et al. 2008).

\subsection{More than trouble and more than expertise}

The final two papers discuss diagnostic work not just as a response to an injured or troublesome party of some sort, whether human (Paoletti, Nevile, this issue) or machine (Alby and Zucchermaglio; Watts-Perotti and Woods; Castellani et al., this issue) but also as arising out of attempts to understand the workings of new technology, which may in fact be functioning perfectly correctly. The diagnostic work here is part of the mundane work of learning to use new software (Arminen and Poikus, this issue) or of setting up a new infrastructure (Poole, Edwards and Jarvis, this issue). In these cases diagnosing is not just about troubles (what has gone wrong?), but also procedural 'what's the next step?', it is about potential (how could/should I use this technology?), and interdependencies (what is connected and how?).

Arminen and Poikus address a commanding trend of neo-bureaucratic reforms in their paper Diagnostic reasoning in the use of a travel management system. They describe how users struggle to understand a new travel self-management 
system, meant to help academics organise their work trips and claim expenses for those trips, without the need for administrators. Based on the reduction of administrative work such systems are supposed to enable, a leaner administrative layer is envisaged, centralised into only one national centre. Arminen and Poikus show how diagnostic reasoning unfolds as the academics strain to make the system work, not because the system is faulty but because they do not understand how it works. The academics are trying to 'diagnose' what the system is doing, and why it responds in the way it does, what they should do next and so on.

The analysis illustrates how this is made difficult because the design of the system actively hampers diagnostic work. On the surface, categories and interface design appear to fit the academics' common sense understandings of travel management, but underneath they invisibly embody administrative knowledge and models of travel management procedures that run counter to it. For example, while menus seem to allow separate creation of both new travel plans and new travel claims, when users try to create new travel claims, error messages appear. This is because the term 'new' in 'new travel claim' has particular administrative meanings that differ from its everyday meanings. Creating a new travel claim is an exceptional case and requires particular actions. If the aim is to create a travel claim for an existing travel plan, the academics need to open the travel plan in question and 'change' it to a travel claim (which was automatically created when they first made their travel plan). To make matters worse, error messages, too, use terms like 'row' in a way that suggests commonsense meanings (interpreted by the users as referring to the first row in the travel claim form on the screen, for example, not least because that is where the message pops up). However, these terms invisibly embody administrative-technical knowledge of database structures and processes. This design strategy only allows very 'flat' and immediate forms of diagnostic reasoning.

The academics are not, nor are they meant to be, administrators. Arminen and Poikus reveal how, nevertheless, the system was designed with attention to the concepts, needs and practices of administrators, making the appropriation of this new technology difficult and ironically now requiring support from administrators whose work the system was designed to supplant. The paper reveals the everyday nature of diagnostic work which people engage in when they interact with new technology or technology that does not behave in the way they expect. Arminen and Poikus' discussion draws on Suchman's (1987, 2007) analysis of triadic interaction sequences between people and machines and compellingly illustrates how technologies designed to enable non-administrators to carry out so-called simple administrative tasks actually breach and thereby reveal the complexity of those tasks (see article of Erickson et al. 2008 on the skills and competencies of administrative assistant work which so often gets sidelined in the rush to develop task-based systems designed to do away with the need for such assistants).

Finally, Poole, Edwards and Jarvis' paper The home network as a sociotechnical system: Understanding the challenges of remote home network problem 
diagnosis describes diagnostic work around wireless home networking. Poole et al. analyze the interactions between home users and call takers in a help centre for wireless routers, where, in most cases, it is opaque whether problems lie with the technology (a blend of software, hardware, infrastructure and services provided by different parties), the environment or user actions. Both users and call centre staff have problems in diagnosing how to make the system work.

This is in no small way due to the fact that-similar to the situation Castellani et al. describe - establishing a common understanding is a two-way process in which both parties are simultaneously novices and experts. On the one hand, home users' technical knowledge is often limited, but they have expert knowledge about non-technical aspects of their home network configuration needs (where machines are, who uses them and for what purposes). The technicians on the other hand, may have technical expertise, but lack an understanding of the technical embodiment of routines in the home, and of (in) compatibilities between often heterogeneous and multi-layered elements, putting them at risk of breaking highly valued existing configurations.

Here, too, technical design choices complicate remote diagnosis and repair. In the complex ecosystem of devices, connections and settings, there are myriad potential sources of difficulty and multiple multi-purpose devices with assorted settings and programmes can create potentially troublesome interferences. However, perhaps the most important obstacle to effective diagnostic work is the 'functional invisibility' of infrastructure technologies. Previous research has begun to elaborate the particular difficulties posed by technical infrastructures; Star and Ruhleder (1994) revealed the embedded, transparent and relational nature of infrastructures; Martin et al. (2009) showed the difficultly that professional users had in using or even understanding a particular technical infrastructure. If people have difficulties even understanding and working with infrastructures which are functioning as intended, what chance do they have of diagnosing problems or of mobilizing technologies creatively (Kyng 2007; Büscher et al. 2008)? Indeed, the intangibility of infrastructures mean that the diagnosis of trouble is compounded by the difficulty of knowing whether the problem lies with the functioning of the infrastructure itself or with the users configuration of (or interaction with) it (Poole, Edwards and Jarvis, this issue; Martin et al. 2009). As Poole, Edwards and Jarvis' paper so clearly reveals a problem with diagnosing (and indeed working with) infrastructures is that rarely does anyone, in this case neither callers nor technicians, have access to a holistic view of the network and thus much of the network is effectively invisible to endusers and technicians alike. First steps towards facilitating the kinds of live, dynamic views of assemblies of heterogeneous devices through 'assembly browsers' are described in Andersen and Larsen (2008)

In the other studies of call centres described in this issue (Castellani et al. and Paoletti) the problem for the call taker lies in not having direct access to the ailing object - access is mediated by callers, who for whatever reason may have trouble 
providing the information on the situation that the call taker needs. In Poole et al.'s case, the wireless network itself is not a physical 'thing' it is an infrastructure, and worse, one made and 'owned' by a variety of organisations, of which the call taker's is only one, responsible for only one part of the infrastructure. Therefore even if the call takers were given direct access to the physical scene there is no certainty of their ability to make things work. This inter-organisational element is particularly stark here, since many of the calls were indeed delegated to other parties, who would suffer the same constraints, and - because there is no record of work already undertaken - may well repeat many diagnostic steps. This requirement for recording and making available to helpers the history of troubles is addressed in the technology concepts of Castellani et al, and has even more relevance here where multiple agents may be involved in troubleshooting the same problem.

We have gathered this cluster of phenomena under the heading of 'More than trouble and more than expertise', because Arminen and Poikus' and Poole, Edwards and Jarvis's analyses reveal that diagnostic work is also about what technologies could or should be doing, implicit assumptions about work processes or material circumstances, as well as multi-layered connections amongst heterogeneous elements. These require more than expertise to address them, not least of all because they are hard even for experts to perceive.

\section{Discussion}

'From its simplest to its most complex forms, perception is essentially a diagnosis' (Spencer 1855, p. 170).

As this quote from the Victorian polymath Herbert Spencer shows, the issues discussed in this special issue have been grappled with for more than 150 years. Diagnosis is not just something medical doctors do, it is far more pervasive in making and holding worlds together. Spencer tried to explain perception by highlighting its diagnostic nature, but this move is circular. As our understanding has evolved, most significantly through naturalistic studies of perception, for example, seeing (Garfinkel 2002; Goodwin 1997), smelling (Teil, quoted in Latour 2004), touch (Goodwin 2009b) as well as epistemic practices (Lynch 1993) such as discovery (Garfinkel et al. 1981) or decision making (Boden 1994), it has become clear that inquiries into perception, knowledge, judgement, and diagnosis must attend to the everyday methods and practices of perceiving, making sense, assessing, deciding and diagnosing. The authors in this special issue ask where, when and how is diagnostic work done? How are these specific activities organised in these specific situations? As the papers show, attention to diagnostic work reveals that diagnosing is not all done in individual minds of experts, but requires sophisticated and delicately negotiated intellectual and 
embodied, collaborative and cooperative, co-present and distributed, expert and non-expert practices. Moreover, diagnostic work involves many actors and agencies, in whose interactions diagnosis often becomes deeply entangled with action and intervention.

The studies detail a wide range of mainly non-medical settings, which helps develop useful analytical sensitivities and insights. We hope to have shown that by stretching a member's category to an analyst's category we can study and reason about important practices effectively. Contributors have looked at diagnostic work and reasoning in problem solving, decision making, anomaly response, troubleshooting, emergency despatch communication and the appropriation of new technology. We all have creatively (but with great empirical care) brought an analytic orientation to diagnostic work to activities which practitioners may not necessarily (without prompting) describe as diagnostic. While this has been extremely powerful in our view, it is also potentially unsettling, as it can be difficult to know where to stop the stretching. Clearly there are many differences between the subject matters of the papers, but their resemblances suggest that this risky business of stretching the term diagnostic work has, for now, interesting pay offs.

The forms of naturalistic investigation employed by the papers presented here have long proven useful for CSCW because they reveal socio-technical practices in a way that, on one hand can specify why some technologies do not support work, and on the other inspire careful design that might work. More ambitiously, designing for diagnosing is an exploration and formulation of different notions of causality (Dekker 2005; Martin et al. 2006; Barad 2007; Suchman 2007), not focused on singular causes and effects, but entanglements; not focused on expert observers 'diagnosing' after gathering and weighing up information, but analysts who are aware that they are acting from within, with situated, partial knowledge. For CSCW this has 'substantive' implications in that designers can and should design technologies that support people in navigating and negotiating these processes. Another aspect of this is that CSCW is not only about supporting cooperative work but also about enabling people to make underlying models built into technologies visible, for example, to support users in interpreting collaborative procedures, and in evaluating their rationale and implications (Schmidt and Bannon 1992). Indeed the latter is integral to the former. This commitment to transparency is necessary to support collaboration between people but also, we believe, conducive to supporting to 'communication', interactions, and 'collaboration' with technology.

Finally, more multi-dimensional notions of causality also have methodological implications for CSCW. The papers in this special issue all share an orientation towards designing for diagnosing. Although only one outlines concrete designs (Castellani et al.), all papers suggest that 'design' refers not just to the creation of novel technologies but to more systemic technological, organisational and practical socio-technical innovation, where multiple actors and agencies are 
causally entangled and new ideas and issues emerge in interaction with new technologies or prototypes. While constructive ethnographic studies can be used to identify difficulties, opportunities and multiple interdependencies to inform the design of technological support (Schmidt and Bannon 1992), they could often also benefit from being more closely braided into interventions, as (as Castellani et al. show) experimental implementations provide opportunity for deeper diagnosis. A focus on diagnostic work in 'target' domains for CSCW can usefully sensitize designers for a reflexive look at design practice. Such reflection suggests to us that closer connections with the collaborative and participatory design community where powerful ways of negotiating practical politics and located accountabilities of socio-technical innovation (Suchman 2002) have been developed would be useful.

\section{Acknowledgements}

We thank Paola Amaldi, Wendy Ark, Patrick Grommes, Susan Hansen, Per Linde, Jonas Kuschel, Leonardo Ramirez, Toni Robertson, and Gunnar Stevens for their insights, experiences, views and ideas in discussing diagnostic work. We thank Dawn Goodwin, Mark Rouncefield and Kjeld Schmidt for encouraging us to pursue this work. Finally, we are indebted to our reviewers and authors for their contributions.

\section{Note}

1. Ethnographies of diagnostic work, 17-18 April 2007 Lancaster University, UK. (http://www.istpalcom.org/diagnosis) and CSCW, Technology and Diagnostic Work, ECSCW 2007, Limerick, Ireland (http://www.ecscw07.org/workshop9.html).

\section{References}

Andersen, P. and S. B. Larsen (2008): (Eds.) PalCom External Report 70: Developer's Companion. Technical Report, PalCom Project IST-002057, April 2008. http://svn.ist-palcom.org/svn/palcom/ trunk/doc/tex/companion.pdf.

Anderson, S., M. Hartswood, R. Procter, M. Rouncefield, R. Slack, J. Soutter and A. Voss (2003): Making Autonomic Computing Systems Accountable: The Problem of Human-Computer Interaction. Proceedings of the 14th International Workshop on Database and Expert Systems Applications (DEXA'03). 718

Baker, C., M. Emmison and A. Firth (Eds.). (2005): Calling for Help. Amsterdam: John Benjamins, pp. 39-62.

Barad, K. (2007): Meeting the Universe Half-way. Quantum Physics and the Entanglement of Matter and Meaning. Durham: Duke University Press.

Bellotti, V., M. Back, W.K. Edwards, R.E. Grinter, A. Henderson and Lopes, C. (2002): Making Sense of Sensing Systems: Five Questions for Designers and Researchers. Proceedings of the SIGCHI Conference on Human Factors in Computing Systems: Changing Our World, Changing Ourselves (Minneapolis, Minnesota, USA, April 20-25, 2002). CHI '02. ACM, New York, NY, pp. 415-422. 
Bitner, D., F. Boon, M. Careem and G. Threadgold (2008): SahanaGIS: A Rapid Deployment GIS Framework for Disaster Management Humanitarian Relief Operations. Proceedings of the Free and Open Source Software for Geospatial Conference, Capetown 29 September-4th October 2008. http://foss4g2008.org (accessed 15.12.2008).

Bly, S., N. Bill, D. W. Schilit, McDonald, B., and S. Ylian (2006): Broken Expectations in the Digital Home. CHI Extended Abstracts, pp. 568-573

Boden, D. (1994): The Business of Talk. Organisations in Action. Cambridge: Polity Press.

Bouchard, G., and J. M. Andreoli (2007): Soft Failure Detection Using Factorial Hidden Markov Models. The Sixth International conference on Machine Learning and Applications (ICMLA 07), pp. $160-165$

Breese, J., and D. Heckerman (1996): Topics in Decision-Theoretic Troubleshooting: Repair and Experiment. Proceedings of Twelfth Conference on Uncertainty in Artificial Intelligence. pp. 124-132.

Büscher, M., and P. Mogensen (2007): Designing for Material Practices of Coordinating Emergency Teamwork. Proceedings of the 4th International Conference on Information Systems for Crisis Response and Management (ISCRAM). May 13th-16th 2007, Delft, The Netherlands. http:// www.iscram.org/dmdocuments/ISCRAM2007/Proceedings/Pages_419_429_52VTC_01_A_ Designing.pdf.

Büscher, M., M. Kristensen, and P. Mogensen (2008): 'When and How (not) to Trust IT? Supporting Virtual Emergency Teamwork. In F. Fiedrich and B. Van de Walle (eds): Proceedings of the 5th International ISCRAM Conference-Washington, DC, USA, May 2008. Reprinted in International Journal of Information Systems for Crisis Response and Management (2009, forthcoming). http://www.iscram.org/dmdocuments/ISCRAM2008/papers/ISCRAM2008 Buscher_etal.pdf.

Büscher, M., D. Goodwin and J. Mesman (Eds.) (2009) Ethnographies of Diagnostic Work. Oxford: Palgrave (in press).

Chalmers, M. (2003): Seamful Design and Pervasive computing Infrastructure Proc. Pervasive computing 2003 Workshop 'At the Crossroads: The Interaction of HCI and Systems Issues in Pervasive Computing'.

Cussins, C. (1998): 'Ontological Choreography': Agency for Women Patients in an Infertility Clinic. In M. Berg and A. Mol (eds): Differences in Medicine: Unraveling Practices, Techniques, and Bodies. Durham: Duke University Press, pp. 166-201.

Dekker, S. (2005): Ten Questions About Human Error: A New View of Human Factors and System Safety. Hillsdale, NJ: Erlbaum.

De Paula, R., X. Ding, P. Dourish, K. Nies, B. Pillet, D. F. Redmiles, J. Ren, J. A. Rode and R. Silva Filho (2005): In the Eye of the Beholder: A Visualization-based Approach to System Security. International Journal of Human-Computer Studies, vol. 63(1-2), pp. 5-24. doi:10.1016/j.ijhcs.2005.04.021.

Dourish, P. (1995): Accounting for System Behaviour: Representation, Reflection, and Resourceful Action. In M. Kyng and L. Mathiassen (eds): Computers and Design in Context. Cambridge: MIT Press, pp. 145-170

Dourish, P. (2001): Where the Action is: Foundations for Embodied Interaction. Cambridge: MIT Press.

Dourish, P. and G. Button (1998): On "Technomethodology": Foundational Relationships between Ethnomethodology and System Design. Human-Computer Interaction, vol. 13(4), pp. 395-432 (Erlbaum, 1998).

Endsley, M., B. Bolté and D.G. Jones (2003): Designing for Situation Awareness: An Approach to User-Centred Design. London: Taylor and Francis.

Erickson, T., C. Danis, W. Kellog, and M. Herlander (2008): Assistance: The Work Practices of Human Administrative Assistants and their Implications for it and Organizations. Proceedings of CSCW, pp. 609-618 
Flin, R. (2005): Capacity for Crisis Management: Identifying Core Skills of Crisis Managers. Discussion paper. Managing crises in the European Union: A first assessment ESF SCSS Exploratory Workshop, St Maxime, June 25-26, 2005, http://www.eucm.leidenuniv.nl/content docs/flin.doc [accessed 9.3.07].

Floerkemeier, C., M. Langheinrich, E. Fleisch, F. Mattern, and S.E. Sarma (2008): (eds): The Internet of Things. Proceedings of the First International Conference, IOT 2008, Zurich, Switzerland, March 26-28, 2008, Lecture Notes in Computer Science: Information Systems and Applications, vol. 4952

Franklin, S. and C. Roberts (2006): Born and Made: An ethnography of Preimplantation Genetic Diagnosis. Princeton: Princeton University Press.

Garfinkel, H. (2002): Ethnomethodology's Program. Working out Durkheim's Aphorism. Lanham: Rowman and Littlefield.

Garfinkel, H. and H. Sacks (1970): 'On formal structures of practical actions'. In McKinney, J. C., and E. A. Tiryakian (eds): Theoretical Sociology. New York: Appleton-Century-Crofts, pp. 337-366.

Garfinkel, H., M. Lynch and E. Livingstone (1981): The Work of a Discovering Science Construed with Materials from the Optically Discovered Pulsar. Philosophy of the Social Sciences, vol. 11, pp. 131-158.

Goffman, E. (1969): The Presentation of Self in Everyday Life. Harmondsworth: Pelican.

Goodwin, C. (1997): The Blackness of Black: Color Categories as Situated Practice. In L.B. Resnick, R. Säljö, C. Pontecorvo and B. Burge (eds): Discourse, Tools and Reasoning: Essays on Situated CognitionBerlin: Springer, pp. 111-140.

Goodwin, D. (2009a) Agency, Participation and Legitimation: Acting in Anaesthesia. Learning in Doing Series. Cambridge: Cambridge University Press.

Goodwin, D. (2009b) Senses and Sense-Making in Anaesthesia. In M. Büscher, D. Goodwin, and J. Mesman (Eds), Ethnographies of diagnostic work. Oxford: Palgrave.

Hacking, I. (1983): Representing and Intervening. Introductory Topics in the Philosophy of Natural Science. Cambridge: Cambridge University Press.

Hansen, S., T. Robertson, J. Li and Wilson, L. (2007): Advanced Telecollaborative Technology for Remote Diagnosis and Patient Management in Critical Care. ECSCW 2007 Workshop paper. Available at http://www.ist-palcom.org/fileadmin/palcom/activities/ECSCW-diagnosing/papers/ ecscw07-diagnosing-Hansen.doc.

Hartswood, M., R. Procter, M. Rouncefield, R. Slack, et al. (2003) 'Repairing' the Machine: A Case Study of the Evaluation of Computer-Aided Detection Tools in Breast Screening. Proc. ECSCW 2003. Helsinki, pp. 375-394.

Heath, C. and P. Luff (1992): Collaboration and Control: Crisis Management and Multimedia technology in London Underground Line Control Rooms. Computer Supported Cooperative Work, vol. 1, pp. 69-94. doi:10.1007/BF00752451.

Heath, C., M. Sanchez Svensson, J. Hindmarsh, P. Luff and D. vom Lehn (2002): Configuring Awareness. Computer Supported Cooperative Work, vol. 11(3-4), pp. 317-347. doi:10.1023/ A:1021247413718.

Hindmarsh, J. and A. Pilnick (2002): The Tacit Order of Teamwork: Collaboration and embodied Conduct in Anaesthesia. The Sociological Quarterly, vol. 43(2), pp. 139-164. doi:10.1111/ j.1533-8525.2002.tb00044.x.

Houtkoop, H., F. Jansen and A. Walstock (2005): Collaborative Problem Description in Help Desk Calls. In Baker, C., Emmison, M. and A. Firth (eds) Calling for Help: Amsterdam: John Benjamins, pp. 63-89.

Jirotka, M., R. Procter, M. Hartswood, R. Slack, A. Simpson, C. Coopmans, C. Hinds and A. Voss (2005): Collaboration and Trust in Healthcare Innovation: The eDiaMoND Case Study. Computer Supported Cooperative Work, vol. 14(4), pp. 368-398. doi:10.1007/s10606-0059001-0 (CSCW). 
Klein, G. (1998) Sources of Power: How people make decisions. Cambridge, MA: MIT Press, 1998.

Klein, G., R. Pliske, B. Crandall and D. Woods (2005): Problem Detection. Cognition Technology and Work, vol. 7(1), pp. 14-28. doi:10.1007/s10111-004-0166-y.

Kyng, M. (2007): (Ed.) PalCom External Report no 52: Revised Conceptual Framework for Palpable Computing Section I. http://www.ist-palcom.org/publications/deliverables/Deliverable-37-\% 5B2.1.2\%5D-palpability-revised-SectionI.pdf.

Latour, B. (1999): Pandora's Hope. Essays on the Reality of Science Studies. Cambridge, MA: Harvard University Press.

Latour, B. (2004): How to Talk About the Body? the Normative Dimension of Science. Body \& Society, vol. 10(2-3), pp. 205-229. doi:10.1177/1357034X04042943.

Law, J. and M. Lynch (1990): 'Lists, Field Guides, and the Descriptive Organization of Seeing: Birdwatching as an Exemplary Observational Activity. In Lynch, M and Woolgar, S. (eds): Representation in Scientific Practice. Cambridge: MIT Press, pp. 267-299.

Lynch, M. (1993): Scientific Practice and Ordinary Action. Ethnomethodology and Social Studies of Science. Cambridge: Cambridge University Press.

Martin, D., M. Hartswood, R. Slack and A. Voss (2006): Achieving Dependability in the Configuration, Integration and Testing of Healthcare Technologies. Computer Supported Cooperative Work, vol. 15(5-6), pp. 467-499. doi:10.1007/s10606-006-9032-1.

Martin, D., J. O’Neill, T. Colombino, F. Roulland and J. Willamowski (2009). Practical Troubles with Infrastructure and Workflow in Colour Printing. From CSCW to Web 2.0: European developments in ccollaborative design. Berlin: Springer.

Mol, A. (2002): The Body Multiple: Ontology in Medical Practice. Durham: Duke University Press.

Mort, M., D. Goodwin, A.F. Smith and C. Pope (2005): Safe Asleep? Human-Machine Relations in Medical Practice. Social Science \& Medicine, vol. 61, pp. 2027-2037. doi:10.1016/j. socscimed.2005.04.008.

Palen, L. and S. Liu (2007): Citizen Communications in Crisis: Anticipating a Future of ICT Supported Participation. Proceedings of the ACM Conference on Human Factors in Computing Systems (CHI 2007), pp. 727-736.

Pawling, A., N.V. Chawla and G. Madey (2007): Anomaly Detection in a Mobile Communication Network. Computational \& Mathematical Organization Theory, vol. 13(4), pp. 407-422.

Schmidt, K. and L. Bannon (1992): Taking CSCW Seriously. Supporting Articulation Work. Computer Supported Cooperative Work, vol. 1, pp. 7-40.

Schutz, A. (1970): On Phenomenology and Social Relations: Selected Writings. In H. Wagner (ed): The Heritage of Sociology collectionChicago: University of Chicago Press.

Sharrock, W. and R.J. Anderson (1994): The User as a Scenic Feature of the Design Space. Design Studies, vol. 15(1), pp. 5-18. doi:10.1016/0142-694X(94)90036-1.

Shehan, E. and W. K. Edwards (2007): Home Networking and HCI: What Hath God Wrought? In Proceedings of the ACM Conference on Human Factors in Computing Systems, San Jose, CA., April 28-May 3, 2007. New York: ACM, pp. 547-556.

Singh, H., L.A. Petersen and E.J. Thomas (2006): Understanding Diagnostic Errors in Medicine: A Lesson from Aviation. Quality \& Safety in Health Care, vol. 15, pp. 159-164. doi:10.1136/ qshc.2005.016444.

Smart, P. R., N. R., Shadbolt, L. A. Carr and M. C. Schraefel (2005): Knowledge-Based Information Fusion for Improved Situational Awareness. Information Fusion, 2005 8th International Conference, volume 2.

Spencer, H. (1855): The Principles of Psychology. Longman, Brown, Green and Longmans. http:// files.libertyfund.org/files/1394/Spencer_0625_EBk_v4.pdf (accessed 11 January 2009).

Star, S.L. and K. Ruhleder (1994): Steps Towards an Ecology of Infrastructure: Complex Problems in Design and Access for Large-Scale Collaborative Systems. In: J.B. Smith, F.D. Smith and T.W. Malone (eds): Proceedings of the 1994 ACM conference on Computer supported cooperative work October 22-26, 1994, Chapel Hill, North Carolina, United States. pp. 253-264. 
Suchman, L. (1987): Plans and Situated Action. The Problem of Human Machine Communication. Cambridge: Cambridge University Press.

Suchman, L. (2002): Located Accountabilities in Technology Production. Scandinivian Journal of Information Systems, vol. 14(2), pp. 91-105. http://www.e-sjis.org/journal/volumes/volume14/ articles/no2/9_Suchman_ss.91-105.pdf.

Suchman, L. (2007): Human and Machine Reconfigurations: Plans and Situated Actions. 2nd edition. Cambridge: Cambridge University Press.

Sudnow, D. (1978): Ways of the Hand: The Organisation of Improvised Conduct. Cambridge MA: MIT Press.

Thrift, N. (2008): Non-representational Theory. Space | Politics | Affect. London: Routledge.

Tomaszewski, B.M. and A.M. MacEachren (2006) A Distributed Spatiotemporal Cognition Approach to Visualization in Support of Coordinated Group Activity. In B. Van der Walle and M. Turoff (eds): Proceedings of the 3rd International ISCRAM Conference., Newark, (NJ) (USA), pp. 347-351.

Whalen, J. and E. Vinkhuyzen (2001): Expert Systems in (inter)action: Diagnosing Document Machine Problems over the Telephone. In P. Luff, J. Hindmarsh and C. Heath, (eds): Workplace Studies: Recovering Work Practice and Information System Design. Cambridge: Cambridge University Press, pp. 92-140.

Wittgenstein, L. (1998 [1953]): Philosophical Investigations. Oxford: Blackwell.

Woods, D. D. and E. Hollnagel (2006): Joint Cognitive Systems: Patterns in Cognitive Systems Engineering. Boca Raton, FL: Taylor and Francis (Klein 2005) 